\title{
CHEMICAL LIGHT STICKS AS BAIT TO TRAP PREDACEOUS AQUATIC INSECTS: EFFECT OF LIGHT COLOUR
}

\author{
MALLORY MacDONNELL ${ }^{1}$, BARRY R. TAYLOR ${ }^{2}$, \\ AND RANDY F. LAUFF* \\ ${ }^{I}$ Current address: Department of Biology, \\ University of New Brunswick, Fredericton, \\ New Brunswick E3B 5A3, Canada. \\ mallory.macdonnell@unb.ca \\ ²btaylor@stfx.ca
}

\begin{abstract}
We measured the efficiency of floating minnow-traps (Gee traps), unbaited or baited with red, green, blue, or white chemical light sticks (glowsticks) to trap large, predaceous, aquatic beetles (Coleoptera) and bugs (Hemiptera) in 50 fresh water, lentic systems in northern Nova Scotia, Canada. Standard minnow-traps buoyed with Styrofoam ${ }^{\circledR}$ floats were set overnight in a variety of freshwater habitats, including ponds, marshes, bog pools and vegetated lake margins throughout the ice-free seasons over three years, for a total of 695 trap-nights. Giant Water Bugs (Lethocerus americanus) were captured with equal frequency in traps baited with any colour glowstick and in unbaited controls. Brown Waterscorpions (Ranatra fusca) were significantly more abundant in lightbaited traps than in dark controls, and showed a strong preference for green lures over other colours. The large, Vertical Diving Beetle Dytiscus verticalis was caught significantly more than expected with white or red lures and significantly less with green or blue lures; males were caught even less often with green or blue lures than in unbaited controls. Our results reveal a heretofore unknown component of the biology of these insects, and suggest a novel method for simple and effective sampling of aquatic insects in still waters.
\end{abstract}

Keywords: light; trapping; phototaxis; aquatic insects; colour

\section{INTRODUCTION}

Many methods are in use, or have been tried, to catch freeswimming (nektonic) aquatic insects such as Predaceous Diving Beetles (Dytiscidae) and Giant Water Bugs (Belostomatidae), yet the standard piece of equipment remains the D-net (Larson et al. 2000).

* Author to whom correspondence should be addressed: rlauff@stfx.ca 
Collecting insects by sweeping with nets provides only crudely quantitative density estimates and is restricted to shallow water. Bottle traps, which trap insects in wide-mouthed jars with a funnel opening, are less destructive to the substratum and vegetation than D-nets, and effectively capture fast-swimming beetles that evade nets (Aiken and Roughley 1985). Bottle traps can be bulky and fragile (Henrikson and Oscarson 1978; Aiken and Roughley 1985; Downie et al. 1998), and submerged traps may drown air-breathing insects. Bottle traps are sometimes baited with fish or meat to attract predaceous insects, but there is no clear evidence that such baiting improves capture success.

Although motile aquatic insects are attracted to light when in flight, and light is routinely used to attract nocturnal flying insects, light-baited traps have rarely been used to collect specimens from water. The few light traps described in the literature have each been designed for a single study, and no standard method has emerged (e.g., Husbands 1967; Espinosa and Clark 1972; Aiken 1979). Moreover, most conventional light sources are impractical for field work, especially in water or at isolated sites. Electric generators and a variety of batteries have been used as power sources for light traps, but these can be unwieldy because of their weight and size, or are dangerous near water (McCafferty 1983). Early attempts to use light as an attraction include sealing a flashlight inside a Mason ${ }^{\circledR}$ Jar, which was then inserted into a large bottle-trap (Hungerford et al. 1955). Aiken (1979) used a $12-\mathrm{V}$ car battery to power a single light trap which measured over $60 \mathrm{~cm}$ long. This device may not be practical for routine field use.

Technological advances have made chemical light sources cheap and readily available. Glowsticks, or snaplight chemical light sticks, are an alternative light source which do not require an external power source; once activated, they produce light for 8-12 hours (Williams et al. 1996). Glowsticks are compact, submersible (and float), inexpensive, non-toxic, practical to take into the field, and simple to use. Despite the evident advantages of light sticks in safety and convenience, there are few published studies on the effectiveness of non-electric light sources such as chemical light. Traps composed of a submerged can with a funnel entrance, baited with glowsticks, have been used to catch nektonic aquatic insects by Lancaster and Scudder (1987) and Williams et al. (1996), but neither of these studies evaluated the efficacy of the light bait. 
Similarly, there have been no studies comparing the effectiveness of different light colours (wavelengths) for capturing aquatic insects. In the past, traps have usually been baited with white light (widespectrum) sources, although black light (long-wave ultraviolet, UV-A) was tried by Carlson $(1971,1972)$, who found it useful for catching Diptera, but not Coleoptera. Neither Lancaster and Scudder (1987) nor Williams et al. (1996) mention the colour of glowstick they used in their submerged traps; chemical light sticks in various colours may not have been available at the time of these studies.

There is reason to expect that light of different colours may be differentially effective for attracting aquatic insects, because of the range of wavelength sensitivities of insect visual perception and the differential absorption of long-wave radiation (red and infra-red) by water. Most insects appear to have a trichromatic colour perception system, with absorption peaks in the ultraviolet, blue and green wavelengths (Briscoe and Chittka 1991). Therefore, these insects cannot perceive red light. Red-blindness is not universal, however (Peitsch et al. 1991, Johnson and Bond 1994, Crook et al. 2009) and the enormous diversity of insect species and life histories suggests that visual capabilities may be similarly varied (Briscoe and Chittka 1991).

The issue is complicated by insect perceptions of light polarization. Aquatic insects in flight, including bugs and beetles, detect water by sensing horizontally polarized light reflected from the surface (Horváth and Kriska 2008, and references therein). This mechanism depends on detection of both the degree and angle of polarization, and may respond to light in the visible and ultraviolet range (Schwind 1991, 1995). The same perceptual system may help aquatic insects distinguish preferred habitat under water. Thus, in addition to wavelength and intensity, insects may use light polarization to provide information about the aquatic environment (Schwind 1995). Flying aquatic insects respond to polarization of light in long wavelengths that they cannot otherwise perceive (Horváth and Kriska 2008).

The purpose of this study was to test the efficacy of light-baited traps for capturing large, predaceous aquatic insects in lentic fresh waters. Our tests were designed to catch three kinds of insect that are seasonally abundant in regional standing waters: large Predaceous Diving Beetles (Dytiscidae), Giant Water Bugs (Lethocerus americanus (Leidy), Hemiptera: Belostomatidae) and Brown Waterscorpions (Ranatra fusca Palisot de Beauvois, Hemiptera: Nepidae). 
We tested the efficiency of glowsticks as light bait in minnow traps (Gee traps), and compared four easily available colours: red, green, blue and white, to see if the insects showed a colour preference or an aversion.

\section{METHODS}

Insects were collected from freshwater ponds, small lakes, marshes, and bogs in northern mainland and northern Cape Breton, Nova Scotia, Canada, during the ice-free seasons (May to October) from 2011 to 2013. The main study site, accounting for more than half of all trap-nights, was Dagger Woods Marsh (centred at $45^{\circ} 35.98^{\prime} \mathrm{N}$, $61^{\circ} 50.38^{\prime} \mathrm{W}, 14 \mathrm{~km}$ east of Antigonish, NS), a 60 -ha wetland complex created in 1988 by damming the outlet stream. Vegetation in the marsh is largely emergent macrophytes, mostly sedges (Carex spp. L.), as well as floating-leaved and submerged aquatic macrophytes, especially white water-lily (Nymphaea odorata Aiton), cow-lily (Nuphar variegata Engelm. ex Durand), watermilfoil (Myriophyllum spp. L.) and pondweed (Potamogeton epihydrus Raf.). The wetland has a broad, slow-flowing central channel and innumerable smaller channels reticulating among islets of emergent vegetation. Dagger Woods Marsh was chosen for intense study because its large size permitted ten minnow traps to be laid at one time, and because preliminary sampling there in 2011 revealed a robust community of predaceous diving beetles. In contrast to the remaining sites, Dagger Woods Marsh also supports a dense population of Northern Redbelly Dace (Chrosomus eos Cope), as well as other small fishes.

Sampling sites outside Dagger Woods Marsh were mostly small to medium sized, (0.01 to 0.2 ha) fishless ponds in Antigonish County, though sites in adjacent Guysborough County and in or near Cape Breton Highlands National Park were sampled as well. We preferred fishless ponds to reduce by-catch, mostly dace, and because preliminary sampling showed capture success was much greater in those sites compared with ponds with fish. Sites sampled included farm ponds, natural woodland ponds, open-water pools in marshes or other wetlands, river floodplain ponds, marshy bays along lake margins, and rain-fed ponds in bogs. We preferred ponds $<2 \mathrm{~m}$ deep with emergent and submergent vegetation to act as habitat for 


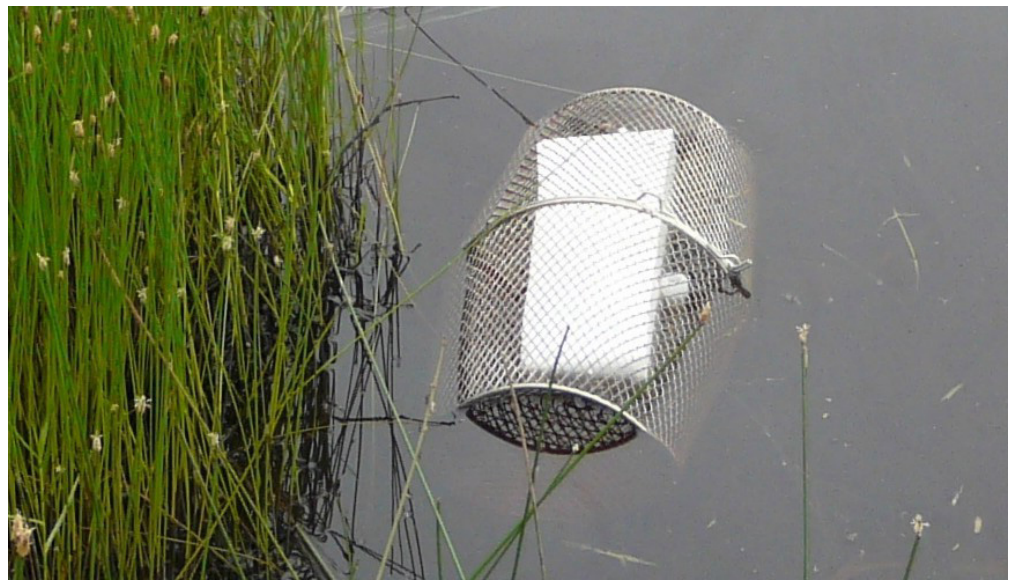

Fig 1 A light-baited trap set in a wetland pool. Note the end of the glowstick to the right of the Styrofoam ${ }^{\circledR}$ float.

predaceous, nektonic insects. In all, we set 695 minnow traps in 50 waterbodies across northern Nova Scotia.

The traps used were conventional minnow traps, also known as Gee traps (Cabela's Canada, Fig 1). The traps are barrel-shaped, with a maximum diameter of $22.2 \mathrm{~cm}$, tapering to $17.8 \mathrm{~cm}$ ends, and mesh openings of $1.1 \times 0.64 \mathrm{~cm}$. Each end of the traps invaginates into a tapering, funnel-shaped cone leading to a $2.5 \mathrm{~cm}$ opening which guides insects to enter but hinders their escape. A white Styrofoam ${ }^{\circledR}$ block, $4 \times 6 \times 25 \mathrm{~cm}$, was placed inside each trap to provide buoyancy, so the traps floated horizontally, with the openings completely submerged ( $7 \mathrm{~cm}$ deep) but with the top of the trap above the water surface; this arrangement allowed trapped insects access to air and ensured that trapping occurred at the same depth (i.e., the surface) in each trial. A $15 \mathrm{~cm}$ glowstick (MagicLight, Montréal, Québec) radiating light in one of the four tested colours (red, green, blue, white; Table 1), was placed in each trap, except in controls, which were left unbaited. The unanchored glowsticks floated vertically, mostly submerged, so light being blocked by the foam float was negligible.

Wherever possible, minnow traps were set in groups of five, one control (no glowstick) and four traps each with a different colour of glowstick, but fewer or more were sometimes set depending on the size of the pond and availability of materials. Replicate sampling among ponds and across years was balanced so the total number of 
Table 1 Peak emission wavelengths of the four glowstick colours. Light spectra were measured with a Sekonic SpectroMaster C-700. Light intensity was measured with a Hannah Instruments HI 97500 portable lux meter.

\begin{tabular}{lcc}
\hline & $\begin{array}{c}\text { Colour } \\
\text { Wavelength (nm) }\end{array}$ & $\begin{array}{c}\text { Peak } \\
\text { Intensity (lux) }\end{array}$ \\
\hline red & 643,655 & 9 \\
green & 517 & 23 \\
blue & 453 & 10 \\
white & $439,553,584$ & 12 \\
\hline
\end{tabular}

trap-nights baited with each colour is very similar in the final data set (133-140). Traps were set at least $10 \mathrm{~m}$ apart at the deep-water margin of the littoral zone or the edge of a channel, near aquatic vegetation, but in water deep enough for the trap to float above the bottom. Traps were set near dusk, tethered by a line to a stake or shrub on shore, and collected early the following morning, when the glowsticks were still glowing; therefore, a trap-night was always 10-12 h. The colour of the lure used to bait each trap was determined by blindly pulling a glowstick out of a pocket; a dead glowstick indicated that the next trap would be an unbaited control.

Two complete sets of minnow traps (four colours plus control, 10 traps) were set in Dagger Woods Marsh on four occasions in May and June 2011, on 10 occasions in May 2012, and twice-weekly (22 May - 10 June) or weekly until 28 October 2013 (25 occasions, missing two weeks in early October). More intense sampling in spring aligned with the maximum abundance of adult dytiscids (Larson et al. 2000) . Coordinates for ten permanent trap locations, evenly distributed along $350 \mathrm{~m}$ of the main channel, were taken in spring each year using a handheld GPS (Garmin GPSmap 60Cx). Traps were placed at the margin of the central channel, among water-lilies and submergent vegetation, then secured with a line to a stake driven into a sedge island. On each sampling occasion, the first five minnow traps were randomly assigned one of the coloured glowsticks or to be a control; the second five traps were laid out in the same pattern as the first five.

Trapping outside Dagger Woods Marsh proceeded from May to August, 2011, March to May 2012, and May to early July in 2013.

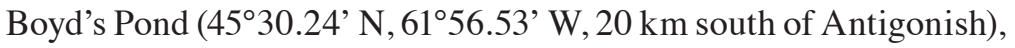
a fishless, $250-\mathrm{m}^{2}$ modified bog pond, $<1 \mathrm{~m}$ deep, was sampled on 
12 occasions over three years; all other sites were sampled once or twice.

Insects caught in the minnow traps were either transported in labelled jars to the laboratory to be curated for the permanent collection, or identified, sexed (some Dytiscidae) and released. Most insects captured in Dagger Woods Marsh were released. Bycatch such as fish and amphibians was released after being identified. Non-target insects (e.g., nymphs of Odonata, Trichoptera) or other invertebrates (e.g., snails) were released. Mortality in the traps was extremely rare.

Colour preferences were revealed through Chi-square analysis of numbers caught in traps baited with each glowstick colour, using equal probability of capture by each colour as the null hypothesis. Each analysis was run once to determine whether numbers were proportionately greater in baited traps than in controls, then again to discern differences among colours. Further Chi-square analyses were run on some subsets of the data to examine specific colour preferences more closely. Data from all sites and times were combined for analysis. A separate analysis was performed for Dagger Woods Marsh alone. For the dominant predaceous diving beetle (Dytiscus verticalis Say, Coleoptera: Dytiscidae), analyses were done for males and females separately, and for all animals combined, which included individuals for which sex was not determined. Giant Water Bugs and Brown Waterscorpions were not separated by sex.

Light-baited minnow traps intended to capture insects sometimes also captured tadpoles, adult amphibians and small fish (see Results). Because tadpoles and fish are prey for predaceous aquatic insects, our target organisms could be attracted to traps containing by-catch, potentially biasing attempts to distinguish light colour preferences. We examined possible sampling bias caused by Green Frog tadpoles (Rana clamitans melanota Rafinesque) and Northern Redbelly Dace by far the most common and abundant elements of by-catch, by testing whether these species showed an attraction or aversion toward any of the four light colours (Kruskal-Wallace Test), and looking for correlations with numbers of predaceous insects captured in the same traps (Spearman Rank Correlation). All species and sexes of Dytiscidae were combined for this analysis.

Tests with tadpoles used data from all sites and years, except Dagger Woods Marsh in 2011, when no tadpoles were captured. Tests with dace used data from Dagger Woods Marsh only, 2011-2013. 
Because we preferred fishless ponds, very few fish were captured outside Dagger Woods Marsh. Traps that captured no organisms were omitted from the analysis.

\section{RESULTS}

Among the large predaceous diving beetles, our traps caught Dytiscus verticalis, D. harrisii Kirby, D. dauricus Gebler, and D. fasciventris Say, but only the first of these was caught in numbers sufficient for analysis. The traps caught a total of $280 \mathrm{D}$. verticalis (164 male, 48 female, 68 unassigned), 90 adult Lethocerus americanus and 196 adult Ranatra fusca. In Dagger Woods Marsh, captures of $D$. verticalis were most successful in early spring and declined swiftly after mid-June (Fig 2A). L.americanus, while less frequent, showed a more or less normal distribution across the sampling season, with a peak in early August (Fig 2B). R. fusca showed a barely discernable decline from a peak in late May (Fig 2C). Hence, our sampling included both times of abundance and scarcity for all three species

Dytiscus verticalis (total) showed a statistically significant difference in capture rate among trap bait colours, including unbaited controls $\left(\mathrm{X}^{2}=24.3, \mathrm{df}=4, \mathrm{p}<0.01\right)$, as did males $\left(\mathrm{X}^{2}=22.6, \mathrm{p}<0.01\right)$ and females $\left(\mathrm{X}^{2}=10.4, \mathrm{p}<0.05\right)$ separately (Fig 3$)$.

Removing the unbaited control traps, i.e., comparing only among different coloured lures, produced essentially identical results (males, $\mathrm{X}^{2}=22.6, \mathrm{p}<0.01$; females, $\mathrm{X}^{2}=8.8, \mathrm{p}<0.05$; total, $\mathrm{X}^{2}=21.9, \mathrm{p}<0.01$ ). In total counts (which are dominated by males) and counts for males separately, there is a clearly higher capture rate in traps baited with white or especially red light compared with green or blue light (Fig 3). Among female beetles, only the difference for red light is apparent; other colours produced capture rates not very different from unbaited traps. This result must be tempered by the low numbers of female beetles captured. Unexpectedly, capture rates for male beetles in traps baited with green or blue lures were significantly less than those in dark, unbaited traps $\left(\mathrm{X}^{2}=4.7, \mathrm{df}=1, \mathrm{p}<0.05\right)$. These colours apparently repel male beetles instead of attracting them.

L. americanus was the only species which showed no significant difference in capture rate among traps baited with different coloured lights $\left(\mathrm{X}^{2}=5.8, \mathrm{df}=4, \mathrm{p}>0.10\right)$, and no difference among lights 

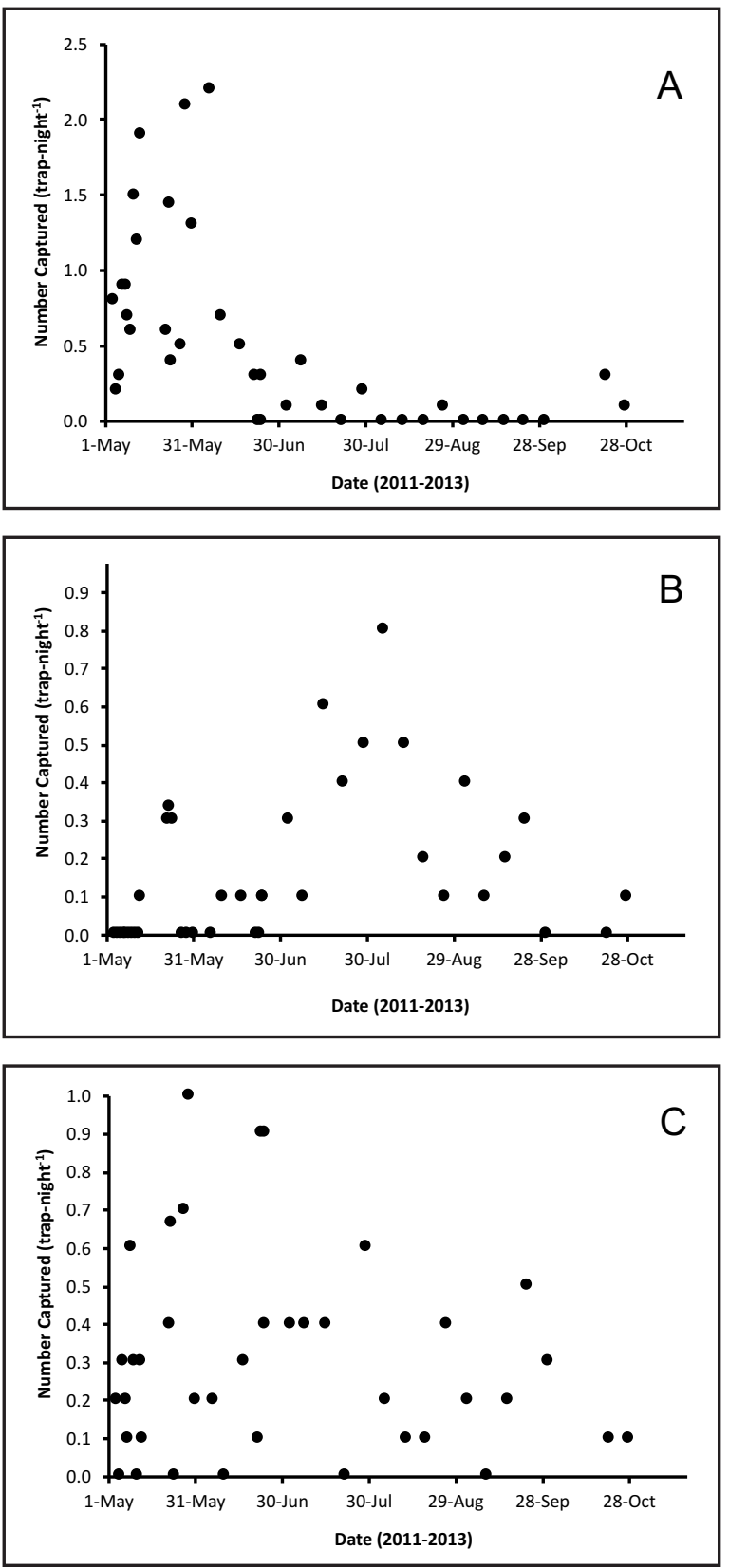

Fig 2 Temporal distribution of adult (A) Dytiscus verticalis (B) Lethocerus americanus and (C) Ranatra fusca captures in light-baited traps set in Dagger Woods Marsh, Nova Scotia, based on combined data from 2011-2013. 


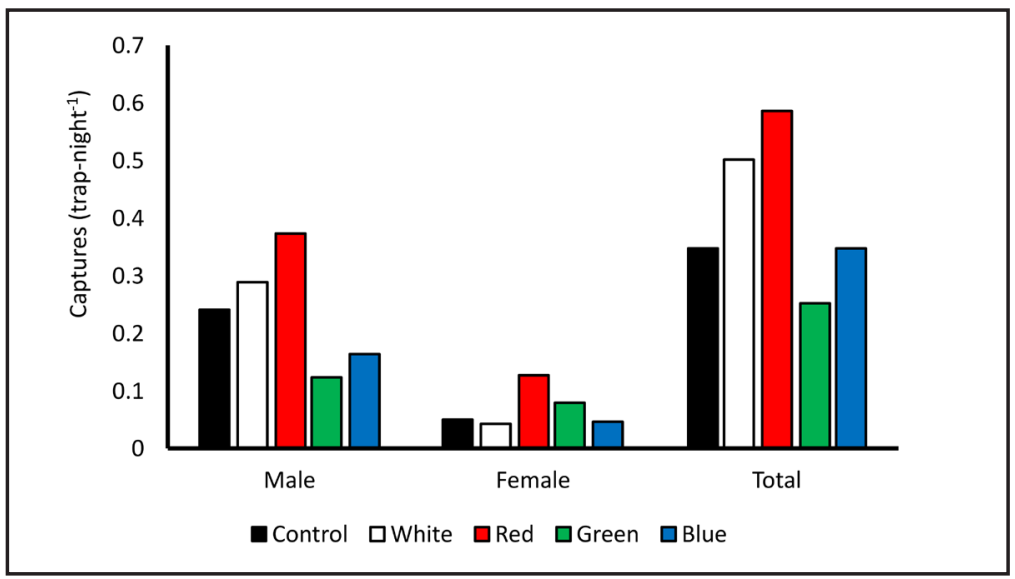

Fig 3 Rate of D. verticalis captures per trap-night in floating Gee traps baited with glowsticks of different colours, based on data from all sampled sites, 2011-2013.

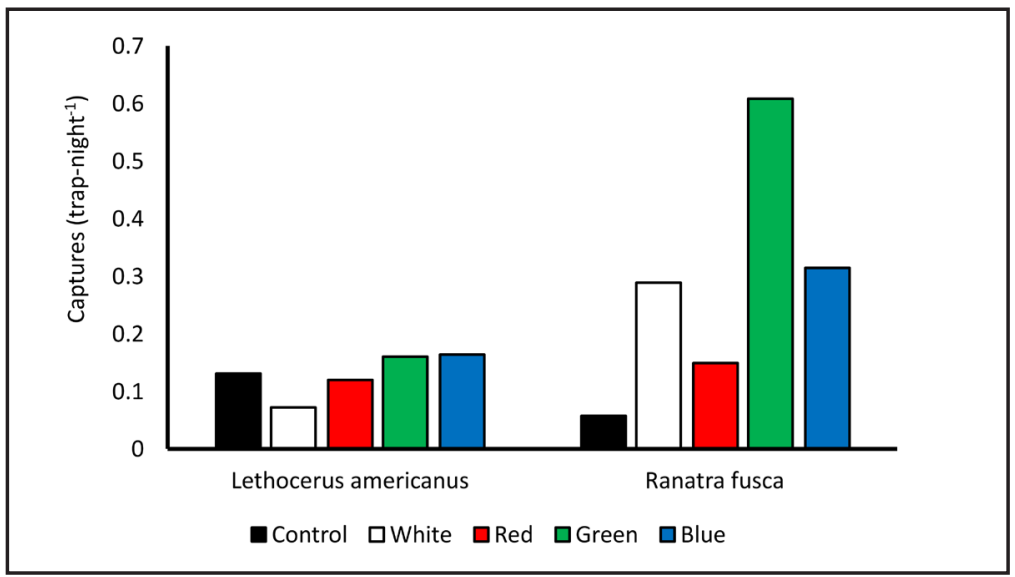

Fig 4 Rates of capture per trap-night of Lethocerus americanus and Ranatra fusca in floating Gee traps baited with glowsticks of different colours, based on data from all sampled sites, 2011-2013.

and unbaited controls $\left(\mathrm{X}^{2}=5.8, \mathrm{p}>0.10\right)$. Giant Water Bugs appear indifferent to whether a trap is baited with light or not (Fig 4).

In contrast, Ranatra fusca shows a highly significant difference in frequency trapped according to colour of the lure when controls are included $\left(\mathrm{X}^{2}=85.4\right.$, $\left.\mathrm{df}=4, \mathrm{p}<0.001\right)$, which remains strong when only light colours are compared $\left(\mathrm{X}^{2}=45.3, \mathrm{df}=3, \mathrm{p}<0.001\right)$. Light-baited traps were far more effective than unbaited traps at 
capturing Brown Waterscorpions (Fig 4). R. fusca was trapped conspicuously more often in traps baited with green light than other colours, and was least attracted to red light.

Results of Chi-square tests on data from Dagger Woods Marsh (not shown) were identical to those from the whole data set, except that there were no significant differences among bait colours for female D. verticalis. Only 37 identified females were captured in Dagger Woods Marsh, compared with 155 males (207 total). Sixty L. americanus and 117 R. fusca were captured in Dagger Woods Marsh.

A total of 503 Green Frog tadpoles were captured in 644 traps. Among the 389 traps that captured at least one organism, the median, first quartile, and third quartile number of tadpoles in a trap are all zero. Most tadpoles were captured in a few traps. The Kruskal-Wallace Test, based on 60-105 replicates of each light colour, revealed no significant difference in tadpoles captured among glowstick colours, or between baited traps and controls $(\mathrm{P}=0.26)$. Spearman correlation showed weak but significant negative correlations between tadpoles and total dytiscids $\left(\mathrm{r}_{\mathrm{s}}=-0.26, \mathrm{P}<0.001\right)$, Brown Waterscorpions $\left(r_{s}=-0.10, P=0.043\right)$, Giant Water Bugs $\left(r_{s}=-0.15, P=0.004\right)$, or the sum of all three taxa $\left(r_{s}=-0.37, P<0.001\right)$. Tadpoles were less frequent in traps that contained predaceous insects (Fig 5A).

Results for Northern Redbelly Dace were similar to those for tadpoles. A total of 590 dace were captured in 380 traps in Dagger Woods Marsh. Among the 269 traps containing at least one fish or predaceous insect, the median number of dace is zero ( $3^{\text {rd }}$ quartile: 1). The Kruskal-Wallace Test, based on 45-59 replicates of each light colour, revealed no significant difference among glowstick colours, or between baited traps and controls $(P=0.19)$. Spearman correlation showed a weak but significant negative correlation between tadpoles and total dytiscids $\left(\mathrm{r}_{\mathrm{s}}=-0.25, \mathrm{P}<0.001\right)$ but not with Brown Waterscorpions or Giant Waterbugs. Dace were less frequent in traps that contained dytiscid beetles (Fig 5B).

\section{DISCUSSION}

It is clear from our results that glowsticks are an effective bait to attract nektonic pond insects. The low cost, portability, ease of disposal, and safety (especially compared against electrical devices) of these widely available lures makes them an attractive alternative 

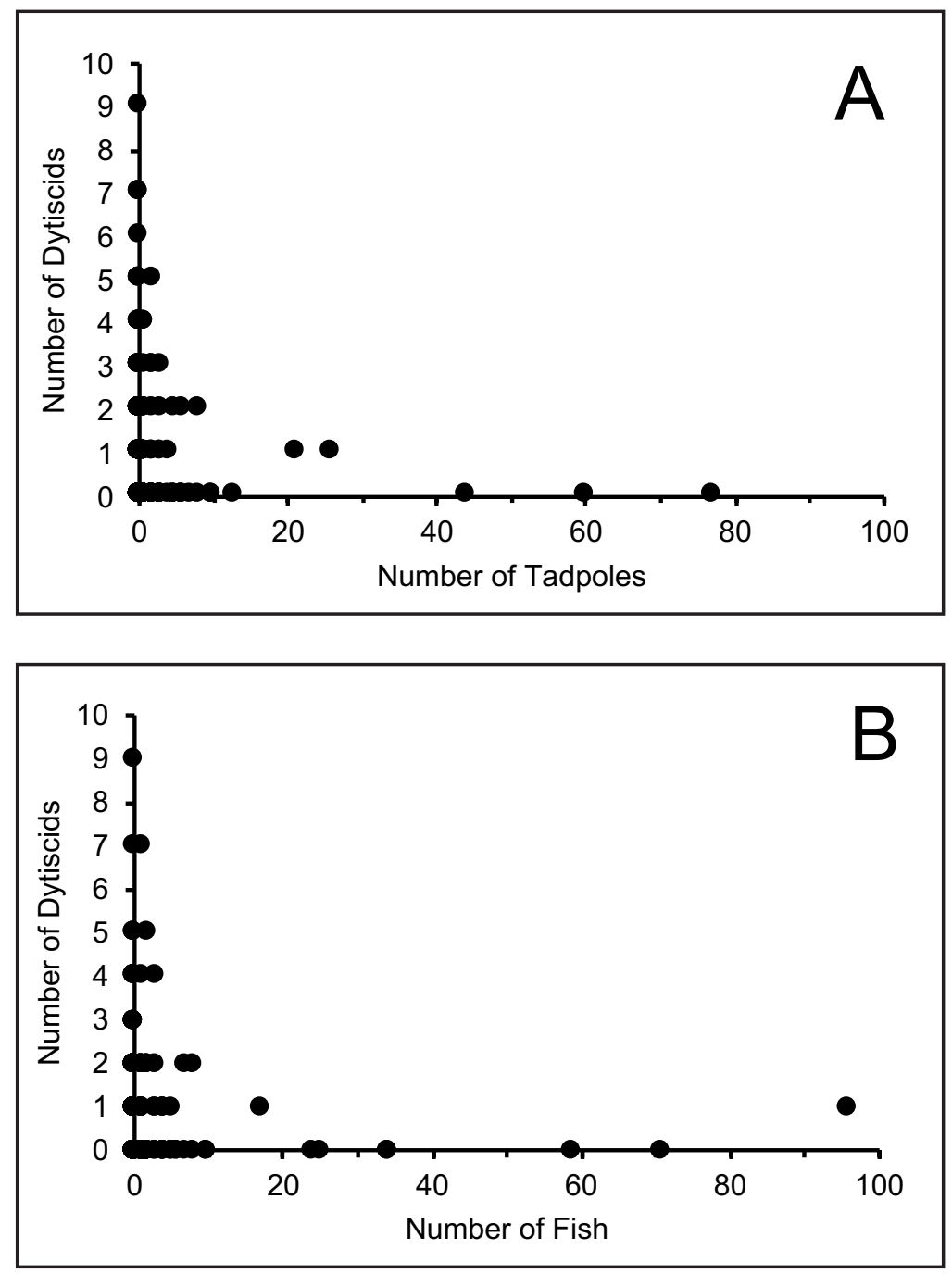

Fig 5 Number of dytiscid beetles captured in each trap compared with the (A) number of green frog tadpoles or $(B)$ northern red-bellied dace caught in the same trap. Data for tadpoles are from 389 traps from all sampled sites and years where tadpoles were encountered. Data for fish are from 269 traps from Dagger Woods Marsh.

for aquatic entomologists. The relatively large mesh size of the minnow traps used in our study limited potential captures to the largest swimming insects. We have tested similar traps with finer mesh which appear to be effective for catching the many smaller 
species of Dytiscidae, as well as Corixidae (water boatmen) and Notonectidae (backswimmers). The limitation on mesh size is that very fine mesh may not let enough light escape to attract insects.

While by-catch, mostly of small fish and tadpoles, was sometimes an issue in our study, the traps do the organisms no harm, and for organisms such as tadpoles, may provide a temporary safe haven from vertebrate predation. Air-breathing organisms have access to the atmosphere in the horizontal, floating traps. Predaceous aquatic insects could be attracted to traps containing prey organisms, irrespective of light colour, but in our data the associations between dytiscids (or other predaceous insects) and fish or tadpoles were negative. It would be maladaptive for predators to avoid confined prey; the negative correlations probably arise from prey organisms avoiding traps containing predators. Moreover, non-insect aquatic life showed no preference for traps baited with glowsticks over unbaited control traps, nor any preference for a particular colour of glowstick.

The negative association between fish and predaceous insects would not arise from predation within the traps. The size of these large insects precludes predation by dace, or indeed any fish small enough to enter the traps. Green Frog tadpoles, being largely herbivorous, would not consume the insects either. Conversely, predaceous insects feeding on trapped fish would leave prey corpses, which were never observed. Hence, the presence of by-catch in some traps does not bias our assessment of glowstick colour preferences by predaceous aquatic insects, and apparently has little influence on effectiveness of baiting with light.

It is also clear that there are important differences among insect species, and even among sexes within the same species, in the attractiveness of glowsticks of different colours. Both systematic, multiyear sampling of one site, Dagger Woods Marsh, and opportunistic sampling across a wide variety of sites and times produced the same results, suggesting our findings are robust. Hence, the optimal colour to use in a particular study will vary according to the objectives of that work. Summarily, red and perhaps white lures are best for $D$. verticalis, and probably other large dytiscids, while green is best to capture $R$. fusca. Baiting with glowsticks does not improve trapping frequency of L. americanus. So strong are these preferences that setting traps with the wrong colour of bait could actually reduce trapping success rather than augment it. 
A fair assessment of glowstick colour as it affects insect trapping must take into account differences in light intensity among glowsticks of different colours along with the perceptual ability of the insects. Light output from white, blue and red glowsticks is similar (9-12 lux), but green glowsticks are much brighter (23 lux). Hence, some of the differences in capture success with different coloured glowsticks as bait may have arisen from the intensity rather than the wavelength of the emitted light. The European nepid Ranatra linearis L., for example, moves toward the water surface at night and downward during the day, following a light gradient (Joly and Cloarec 1980). The conspicuously greater trapping success of $R$. fusca in traps baited with green light could be attributable at least in part to a more intense light proving more attractive than weaker ones, or to the light being perceived at a greater distance.

However, neither of the other two insect species examined showed a preference for green light. L. americanus showed no distinguishable attraction to light of any kind, and green light attracted $D$. verticalis less than white or red sources of lower intensity, or for males, less than no light at all. It cannot simply be the intensity of the light source that accounts for the varying effectiveness of glowsticks of different colours.

A second obfuscating factor is the differential transmission of light of different wavelengths through water. The rapidity with which red light is absorbed, relative to shorter wavelengths (Wetzel 2001) could limit the distance over which the light is perceptible to aquatic organisms and therefore the area from which potential specimens may be drawn. Again, however, this difference does not correspond with the observed effectiveness of glowsticks of different colours. While $R$. fusca was least often trapped in traps baited with red light, relative to other colours, and L. americanus capture was unaffected by lure colour, red glowsticks were more likely to capture $D$. verticalis than were baits of any other colour, or dark traps. The high absorption coefficient for red light in water therefore does not appear to be a significant factor limiting the value of red glowsticks as bait.

Strong responses to red glowsticks are perhaps surprising because many insects are believed incapable of perceiving red light (Briscoe and Chittka 1991). Nevertheless, Kriska et al., (2006) showed that flying aquatic insects, including Dytiscidae and predaceous bugs, were attracted to red or black surfaces because the reflected 
light was horizontally polarized in the blue and green parts of the spectrum, eliciting a positive polarotactic response even if the insects were red-blind. The same response could be elicited by a red glowstick, with reflection in the water providing the polarization. White glowsticks emit a mixture of wavelengths, so the same response, perhaps weaker, would be expected. Crook et al. (2009) showed that compound eyes of female emerald ash borers (Agrilus planipennis Fairmaire (Coleoptera: Buprestidae)) were sensitive to red light, while male's eyes were not. Hence, both the evident response to red light by $D$. verticalis in this study, and the less definite difference between males and females, are consistent with known elements of insect vision.

The remaining question concerns how these differences in trapping frequency with baits of different colours arise. Evidently the glowsticks elicit a positive phototaxis (or in one case, a negative phototaxis) which is stronger for some colours than others and differs among species. Menzel (1979) points out that the difference in spectral composition between sunlight (rich in blue light) and light reflected from plants and soil (rich in yellow-green) could be a cue allowing aquatic organisms to differentiate open space from vegetation or other cover. More generally, the reflection and polarization characteristics of underwater light allow organisms to finely differentiate among habitats (Schwind 1995).

Dytiscids are active predators and scavengers. The differential absorption of light of different wavelengths by water, magnified by dissolved organic matter (Kalff 2002) could provide a useful cue to depth; attraction to red or white light, abundant only near the surface, and avoidance of green and blue light, increasingly dominant at depth, would be consistent with air-breathing organisms seeking to remain near the surface of the pond. These organisms may perceive a blue glowstick as indicative of deep water where they do not belong.

Brown Waterscorpions, Ranatra fusca, by contrast, are sit-andwait predators (Joly and Cloarec 1980). They may perceive green light as an indicator of green aquatic vegetation, their preferred habitat and the habitat of the small fish and tadpoles on which they prey. It would be reasonable then for these organisms to be strongly attracted to glowsticks radiating green light in preference to other colours. Such sensitivity to green light has been observed in other aquatic bugs (Horváth and Kriska 2008). Even within the context of 
this behaviour-based model, the indifference of Giant Water Bugs, Lethocerus americanus, to light bait, despite reports of positive phototaxis in the Belostomatidae (Severin and Severin 1911, Ward 1992, Ohba and Takagi 2005), remains an enigma.

Acknowledgements Funding was provided by the Nova Scotia Museum of Natural History and the Department of Natural Resources via the Nova Scotia Habitat Conservation Fund (contributions from hunters and trappers). Thanks go to the many volunteers who paddled marshes with us and helped in other ways as well. Geniece HalletTapley kindly measured the glowstick absorbances.

\section{LITERATURE CITED}

Aiken, R.B. (1979). A size selective underwater light trap. Hydrobiologia 65 (1): 65-68.

Aiken, R.B., \& Roughley, R.E. (1985). An effective trapping and marking method for aquatic beetles. Proceedings of the Academy of Natural Sciences 137 (1): 5-7.

Briscoe, A.D., \& Chittka, L. (2001). The evolution of colour vision in insects. Annual Review of Entomology 46 (1): 471-510.

Carlson, D. (1971). A method for sampling larval and emerging insects using an aquatic black light trap. The Canadian Entomologist 103 (10): 1365-1369.

Carlson, D. (1972). Comparative value of black light and cool white lamps in attracting insects to aquatic traps. Journal of the Kansas Entomological Society 45: 194-199.

Crook, D.J., Francese, J.A., Zylstra, K.E., Fraser, I., Sawyer, A.J., Bartels, D.W., Lance D.R., \& Mastro, V.C. (2009). Laboratory and field response of the emerald ash borer (Coleoptera: Buprestidae), to selected regions of the electromagnetic spectrum. Journal of Economic Entomology 102 (6): 2160-2169.

Downie, I.S., Coulson, J.C., Foster, G.N., \& Whitfield, D.P. (1998). Distribution of aquatic macroinvertebrates within peatland pool complexes in the Flow Country, Scotland. Hydrobiologia 377 (1): 95-105.

Espinosa, L.R., \& Clark, W.E. (1972). A polypropylene light trap for aquatic invertebrates. California Fish and Game 58: 149-152.

Henrikson, L., \& Oscarson, H. (1978). A quantitative sampler for airbreathing aquatic insects. Freshwater Biology 8 (1): 73-77.

Hilsenhoff, W.L., \& Tracy, B.H. (1985). Techniques for collecting water beetles from lentic habitats. Proceedings of the Academy of Natural Sciences of Philadelphia 137: 8-11. 
Horváth, G., \& Kriska, G. (2008). Polarization vision in aquatic insects and ecological traps for polarotactic insects. in: Lancaster, J. Briers, R. A. (Editors). Aquatic Insects: Challenges to Populations. Proceedings of the Royal Society Symposium pp. 204-229.

Hungerford, H.B., Spangler, P.J., \& Walker, N.A. (1955). Subaquatic light traps for insects and other animal organisms. Transactions of the Kansas Academy of Science 58 (3): 387-407.

Husbands, R.C. (1967). A subsurface light trap for sampling aquatic insect populations. California Vector Views 14: 81-82.

Johnson, S.D., \& Bond, W.J. (1994). Red flowers and butterfly pollination in the fynbos of South Africa. In: Arianoutsou, M. and Groves, R.H. Plant-animal interactions in Mediterranean-type ecosystems. Tasks for Vegetation Science Vol. 31. Springer Netherlands. pp. 137-148.

Joly, D., \& Cloarec, A. (1980). The influence of light intensity on vertical distribution in Ranatra linearis Linnaeus (Heteroptera: Nepidae). Journal of Ethology, 6: 111-119.

Kalff,J.(2002). Limnology: Inland water ecosystems. Prentice Hall, Upper Saddle River, United States of America.

Kriska, G., Csabai, Z., Boda, P., Malik, P., \& Horváth, G. (2006). Why do red and dark-coloured cars lure aquatic insects? The attraction of water insects to car paintwork explained by reflection-polarization signals. Proceedings of the Royal Society B: Biological Sciences 273 (1594): 1667-1671. DOI: 10.1098/rspb.2006.3500.

Lancaster, J., \& Scudder, G.G.E. (1987). Aquatic Coleoptera and Hemiptera in some Canadian saline lakes: patterns in community structure. Canadian Journal of Zoology 65 (6): 1383-1390.

Larson, D.J., Alarie, Y., \& Roughley, R.E. (2000). Predaceous Diving Beetles (Coleoptera: Dytiscidae) of the Nearctic Region, with emphasis on the fauna of Canada and Alaska. National Research Council Research Press, Ottawa, Canada.

McCafferty, W.R.(1983). Aquatic entomology: The fisherman's and ecologists' illustrated guide to insects and their relatives. Jones and Bartlett Publishers, Sudbury, United States of America.

Menzel, R. (1979). Spectral sensitivity and colour vision in invertebrates. In: Comparative Physiology and Evolution of Vision in Invertebrates. Handbook of Sensory Physiology, Springer-Verlag, New York, NY. Volume 7: 503-580.

Ohba, S., \& Takagi, H. (2005). Food shortage affects flight migration of the giant water bug Lethocerus deyrolli in the prewintering season. Limnology 6 (2): 85-90. DOI 10.1007/s10201-005-0148-7.

Peitsch, D., Fietz, A., Hertel, H., de Souza, J., Ventura, D.F., \& Menzel, R. (1992). The spectral input systems of hymenopteran insects and their receptor-based colour vision. Journal of Comparative Physiology A 170 (1): 23-40. 
Schwind,R.(1991). Polarization vision in water insects and insects living on a moist substrate. Journal of Comparative Physiology A 169 (5): 531-540.

Schwind,R.(1995). Spectral regions in which aquatic insects see reflected polarized light. Journal of Comparative Physiology A 177 (4): 439-448.

Severin, H.H.P., \& Severin, H.C. (1911). Habits of Belostoma (=Zaitha) flumineum Say and Nepa apiculata Uhler, with observations on other closely related aquatic Hemiptera. Journal of the New York Entomological Society 19 (2): 99-108.

Ward, J.V. (1992). Aquatic insect ecology: 1. Biology and Habitat. John Wiley and Sons Inc., New York, United States of America.

Wetzel, R.G. (2001). Limnology: Lake and River Ecosystems. $3^{\text {rd }}$ ed. Academic Press, San Diego, United States of America.

Williams, R.N., Ellis, M.S., \& Fickle,D.S. (1996). Insects in the Killbuck Marsh Wildlife Area, Ohio: 1994 Survey. Ohio Journal of Science 96: 34-40. 